\title{
An empirical study to measure the relative efficiencies of training organizations using data envelopment analysis
}

\author{
Ahmad Ahmadkhani ${ }^{a^{*}}$ and Masoud Babakhani ${ }^{\mathrm{a}}$ \\ ${ }^{a}$ Department of Industrial Engineering, Iran University of Science \& Technology, Digital Unit, Tehran, Iran

\begin{tabular}{|c|c|}
\hline AR T I C L E I N F O & A B S T R A C T \\
\hline $\begin{array}{l}\text { Article history: } \\
\text { Received } 1 \text { August } 2010 \\
\text { Received in revised form } \\
\text { 23 November } 2010 \\
\text { Accepted } 23 \text { November } 2010 \\
\text { Available online } \\
\text { 24 November } 2010 \\
\text { Keywords: }\end{array}$ & $\begin{array}{l}\text { This paper presents an empirical study on measuring relative efficiencies of test drive } \\
\text { educational organizations using data envelopment analysis. The study uses a Delphi method to } \\
\text { determine the most important input/output factors and then gathers the actual data for all units } \\
\text { located in an Iranian province called Zanjan. The results of the implementation of the DEA } \\
\text { method are compared for different periods of the recent year and they are analyzed. We perform } \\
\text { the DEA implementation for two separate regions, one for the units located inside the city and } \\
\text { the other for the units located in the rural area. The output results of both methods are compared } \\
\text { and the results are discussed in details. }\end{array}$ \\
\hline
\end{tabular}

Data Envelopment Analysis

Efficiency

Driving test

Performance measurement

\section{Introduction}

During the past two decades, there have been tremendous studies on measuring relative efficiency for non-financial organizations using data envelopment analysis (DEA) (Charnes et al., 1978). DEA is popular among mathematicians and practitioners from different perspectives. Mathematicians mostly consider the method as a good area of research and practitioners look at it as a simple tool for performance measurement (Charnes et al., 1994). The method simply uses some input/output parameters to calculate the relative efficiencies of various units through the adaptation of a linear programming toolbox such as Lingo where even the necessary DEA toolbox is also available. The other advantage of the implementation of DEA is the availability of sensitivity analysis on the use of Simplex method. Therefore, there is no need to resolve a method whenever there are some changes on the input/output parameters. The other advantage of DEA is the capability of using no-financial terms influencing the performance of the organizations. For the past two decades, there have been many evidences to confirm that intangible assets play important role on the success of the firms

* Corresponding author. Tel./fax: +98935 8799109

E-mail addresses: a_ahmadkhani84@yahoo.com (A. Ahmadkhani), 
(Kaplan \& Norton, 1992). Human resources are the most important part of many high-tech organizations (Kaplan \& Norton, 2004). On the other hand, a firm with shortage on fixed assets and money could also face with some challenges. Therefore, there must a good combination of tangible and intangible assets to provide a meaningful efficiency measurement (Najafi et al., 2011). Deller and Rudnicki (1993) studied the efficiency of Maine elementary schools in an attempt to maximize student achievement, given certain student and community specifications and reported a strong relationship between school expenditures and student performance.

Educational systems are good examples of the firms where non-financial factors play important roles on performance measurement. The first experience of DEA implementation belongs to elementary schools in an urban school district (Bessent \& Bessent, 1980). The approach determines the identification of efficient and inefficient schools and provides management information relative to input and output measures. Bessent et al. (1982) implemented DEA to Houston independent school district. Measuring the efficiency of public schools has been a concern over the past several decades for many reasons (Hanushek, 1986). The public schools must run on an economic scale to reduce the unnecessary expenditures. The educational systems normally require significant amount of governments' budget to run and a small decrease on the budget in this part could help other governmental agencies (Ray, 1991, Walberg \& Fowler, 1987). Chakraborty et al. (2001) presented an emperical analysis for measuring the relative efficiency of public schools using stochastic method. Borge and Naper (2006) performed an empirical analysis on measuring efficiency potential and efficiency variation in Norwegian Lower Secondary Schools based on the implementation of DEA approach. Naper (2010) analyzed the relationship between teacher hiring practices and educational efficiency in Norwegian school districts. These evidences clearly show that there is a major concern in different countries for constantly measuring the relative efficiency of educational systems. In this paper, we present a practical approach to measure the relative efficiency of driving test organizations in a major province of Iran. The implementation uses DEA method and using various input/output financial and non-financial data, we study the performance of all units. This paper is organized as follows. We first present the problem statement of the proposed DEA method in section 2. Section 3 explains the details of the implementation of our DEA approach and finally concluding remarks are given at the end to summarize the contribution of the paper.

\section{Problem Statement}

In this section, we present the problem statement of the proposed DEA method used in this paper. In a DEA method, there are normally some inputs and outputs associated with all decision-making units. Let $x_{i j}$ be the inputs for one of decision-making unit with $i=1, \ldots, m$ and $y_{r j}$ be the outputs of the same units with $r=1, \ldots, s$ and $j=1, \ldots, n$ and suppose $u_{i}$ and $v_{j}$ are the dual variables associated with $x_{i}$ and $y_{j}$, respectively. The constant return to scale DEA modeling formulation is as follows,

$$
\begin{gathered}
\max =\frac{\sum_{r=1}^{s} u_{r} y_{r .} .}{\sum_{i=1}^{m} v_{i} x_{i .} .} \\
\text { subject to } \quad \frac{\sum_{r=1}^{s} u_{r} y_{r j}}{\sum_{i=1}^{m} v_{i} x_{i j}} \leq 1 . \\
X_{i j}, y_{i j \geq 0}
\end{gathered}
$$


Model (1) is the basic DEA, which can be solved $j$ times to determine the relative efficiencies of various units. However, since model (1) is nonlinear in structure, Charles et al. (1978) proposed a simple modification of the objective function to convert model (1) into a simple linear programming problem as follows,

$$
\begin{array}{ll}
\max & Z=\sum_{r=1}^{s} u_{r} y_{r .} . \\
\text { subject to } & \frac{\sum_{r=1}^{s} u_{r} y_{r j}}{\sum_{i=1}^{m} v_{i} x_{i j}} \leq 1 . \\
& \sum_{i=1}^{m} v_{i} x_{i .}=1 \\
& u_{r}, v_{i} \geq 0, \quad j=1, \ldots, n
\end{array}
$$

Problem (2) has been widely used for the past three decades and the results are commonly accepted as a tool for measuring the relative efficiencies of various units. There are literally different versions of DEA methods such as input or output oriented models and they are used depending on whether we have control on the output or the input parameters. DEA models have been extended when there are uncertainties associated with inputs/outputs called robust DEA. In robust DEA we consider an acceptable perturbation on each parameters and final solution will not change as long as these parameters change in the interval of uncertainties (Roghanian \& Foroughi, 2010).

\section{Empirical Analysis}

During the past few decades, there has been growing interest on privatization to reduce the cost of running the governments. The governmental agencies try to reduce their direct duties by outsourcing their responsibilities. One of the major responsibilities of governmental agencies is to issue driving license for individual applicants. The entire process of getting driver license includes training, written and driving examinations. The primary concern is to maintain a good quality service to reduce the number of accidents. In fact, one of the major causes of accidents is that drivers are not fully familiar with traffic, driving rules and regulations. Over the past two decades, all parts of the written and driving tests have been handed to private sector. Therefore, there are some organization agencies where applicants can register to training classes. The government is responsible to give the necessary exams and the certificates are granted once applicants pass the required written and practical tests. Once an exam is held, an agent from government must participate in the exam to make sure that no rule is violated. Therefore, a private organization with higher rate of success on exams is not only ideal for the owners but also it is ideal for government. The proposed DEA model of this paper uses four inputs and one output to measure the relative efficiencies of different decision-making units. Fig. 1 shows the input/output parameters of the model.

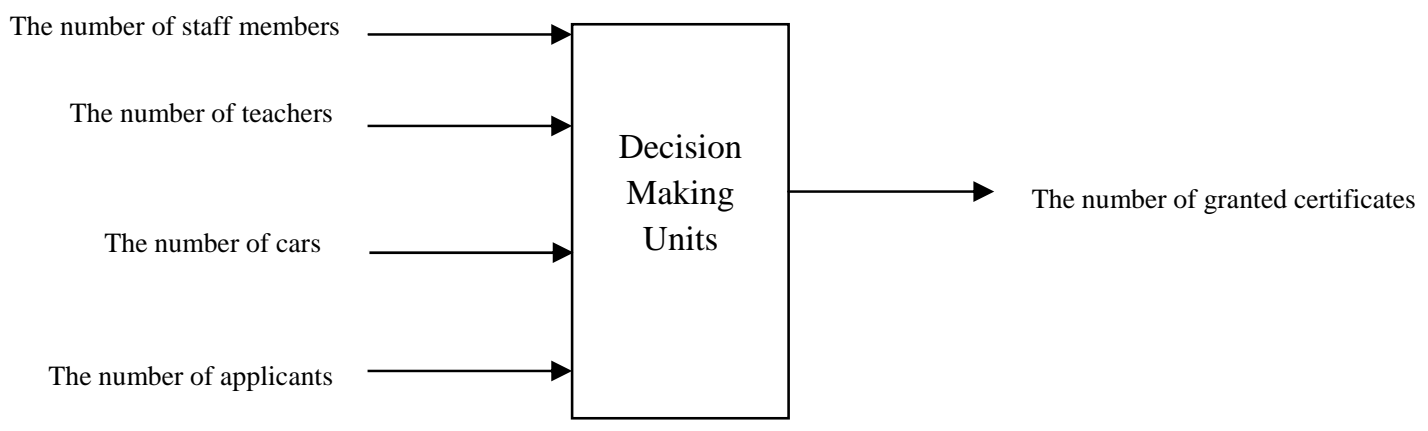

Fig. 1. The input and the output of DEA model 
The study of this paper focused on nine major units located in one of the Iranian cities called Zanjan. Table 1 summarizes the number of staff members, the number of teachers and the number of cars used for training and examination.

\section{Table 1}

The number of input values for the first three inputs for the city of Zanjan

\begin{tabular}{lccccccccc}
\hline Unit & 1 & 2 & 3 & 4 & 5 & 6 & 7 & 8 & 9 \\
\hline Staff & 4 & 4 & 4 & 4 & 4 & 4 & 4 & 4 & 4 \\
Teacher & 30 & 24 & 17 & 18 & 27 & 8 & 20 & 12 & 13 \\
Car & 30 & 21 & 17 & 18 & 26 & 8 & 20 & 11 & 13 \\
\hline
\end{tabular}

Table 2 demonstrates the number of applicants who registered to get the necessary certificates.

Table 2

The number of applicants who registered for exams for the units located in Zanjan

\begin{tabular}{|c|c|c|c|c|c|c|c|c|c|c|c|c|c|c|}
\hline \multirow{2}{*}{$\begin{array}{l}\text { Unit } \\
\text { No. }\end{array}$} & \multicolumn{12}{|c|}{ Months } & \multicolumn{2}{|c|}{ Statistics } \\
\hline & 1 & 2 & 3 & 4 & 5 & 6 & 7 & 8 & 9 & 10 & 11 & 12 & Mean & Std \\
\hline 1 & 160 & 179 & 129 & 292 & 260 & 136 & 187 & 162 & 100 & 114 & 133 & 90 & 162 & 61 \\
\hline 2 & 180 & 210 & 170 & 300 & 300 & 300 & 300 & 200 & 180 & 190 & 240 & 150 & 227 & 58 \\
\hline 3 & 70 & 110 & 88 & 120 & 120 & 142 & 122 & 95 & 117 & 150 & 149 & 100 & 115 & 25 \\
\hline 4 & 109 & 113 & 120 & 165 & 163 & 180 & 147 & 170 & 158 & 129 & 199 & 146 & 150 & 28 \\
\hline 5 & 188 & 207 & 162 & 198 & 259 & 203 & 286 & 211 & 256 & 210 & 139 & 160 & 207 & 43 \\
\hline 6 & 59 & 62 & 50 & 64 & 100 & 77 & 70 & 74 & 52 & 28 & 100 & 67 & 67 & 20 \\
\hline 7 & 92 & 89 & 48 & 126 & 174 & 140 & 65 & 82 & 41 & 83 & 77 & 58 & 90 & 39 \\
\hline 8 & 56 & 45 & 41 & 59 & 122 & 78 & 49 & 51 & 50 & 78 & 57 & 14 & 58 & 26 \\
\hline 9 & 63 & 88 & 71 & 143 & 119 & 119 & 85 & 89 & 73 & 67 & 101 & 54 & 89 & 27 \\
\hline
\end{tabular}

Finally Table 3 summarizes the number of customers who have successfully passed the exams and received certificates.

Table 3

The number of customers who received certificates for the units located in Zanjan

\begin{tabular}{lllllllllllllll}
\hline Unit \\
No. & 1 & 2 & 3 & 4 & 5 & 6 & 7 & 8 & 9 & 10 & 11 & 12 & Mean & Std \\
\hline 1 & 32 & 92 & 163 & 100 & 126 & 145 & 167 & 150 & 149 & 166 & 115 & 162 & 131 & 40 \\
\hline 2 & 174 & 191 & 199 & 108 & 227 & 193 & 206 & 157 & 212 & 198 & 223 & 182 & 189 & 32 \\
\hline 3 & 63 & 85 & 92 & 110 & 90 & 93 & 93 & 79 & 87 & 135 & 94 & 103 & 94 & 17 \\
\hline 4 & 24 & 153 & 111 & 129 & 116 & 139 & 124 & 80 & 76 & 107 & 117 & 106 & 107 & 34 \\
\hline 5 & 71 & 76 & 217 & 155 & 178 & 190 & 140 & 149 & 113 & 208 & 158 & 151 & 151 & 46 \\
\hline 6 & 51 & 71 & 68 & 44 & 66 & 49 & 94 & 55 & 66 & 67 & 45 & 56 & 61 & 14 \\
\hline 7 & 74 & 63 & 78 & 67 & 74 & 121 & 91 & 96 & 81 & 77 & 46 & 26 & 75 & 24 \\
\hline 8 & 0 & 44 & 33 & 37 & 53 & 28 & 60 & 49 & 33 & 44 & 46 & 57 & 40 & 16 \\
\hline 9 & 60 & 71 & 81 & 38 & 76 & 78 & 102 & 80 & 55 & 89 & 55 & 86 & 73 & 18 \\
\hline
\end{tabular}

The DEA model (1) was run for 12 different monthly periods of year 2009 and the results are summarized in Table 4. 
Table 4

The summary of measuring the relative efficiencies of the units located in Zanjan

\begin{tabular}{llllllllllllllllll}
\hline Unit & \multicolumn{1}{c}{ The relative efficiencies of different units for various months } & \multicolumn{3}{c}{ Statistics } \\
\cline { 2 - 18 } No. & 1 & 2 & 3 & 4 & 5 & 6 & 7 & 8 & 9 & 10 & 11 & 12 & Mean & Std \\
\hline 1 & 0.21 & 0.51 & 0.92 & 0.65 & 0.64 & $\mathbf{1 . 0 0}$ & $\mathbf{1 . 0 0}$ & $\mathbf{1 . 0 0}$ & $\mathbf{1 . 0 0}$ & $\mathbf{1 . 0 0}$ & 0.76 & $\mathbf{1 . 0 0}$ & 0.81 & 0.26 \\
\hline 2 & $\mathbf{1 . 0 0}$ & $\mathbf{1 . 0 0}$ & $\mathbf{1 . 0 0}$ & 0.78 & $\mathbf{1 . 0 0}$ & $\mathbf{1 . 0 0}$ & $\mathbf{1 . 0 0}$ & $\mathbf{1 . 0 0}$ & $\mathbf{1 . 0 0}$ & $\mathbf{1 . 0 0}$ & $\mathbf{1 . 0 0}$ & $\mathbf{1 . 0 0}$ & 0.98 & 0.06 \\
\hline 3 & 0.93 & 0.59 & 0.76 & $\mathbf{1 . 0 0}$ & 0.99 & 0.75 & 0.74 & 0.85 & 0.61 & 0.96 & 0.66 & 0.98 & 0.82 & 0.15 \\
\hline 4 & 0.22 & $\mathbf{1 . 0 0}$ & 0.75 & $\mathbf{1 . 0 0}$ & 0.94 & $\mathbf{1 . 0 0}$ & 0.91 & 0.67 & 0.48 & 0.72 & 0.70 & 0.97 & 0.78 & 0.24 \\
\hline 5 & 0.41 & 0.40 & $\mathbf{1 . 0 0}$ & $\mathbf{1 . 0 0}$ & 0.90 & $\mathbf{1 . 0 0}$ & 0.69 & 0.95 & 0.53 & $\mathbf{1 . 0 0}$ & $\mathbf{1 . 0 0}$ & $\mathbf{1 . 0 0}$ & 0.82 & 0.25 \\
\hline 6 & 0.89 & $\mathbf{1 . 0 0}$ & $\mathbf{1 . 0 0}$ & 0.81 & 0.87 & 0.80 & $\mathbf{1 . 0 0}$ & $\mathbf{1 . 0 0}$ & $\mathbf{1 . 0 0}$ & $\mathbf{1 . 0 0}$ & 0.61 & $\mathbf{1 . 0 0}$ & 0.92 & 0.12 \\
\hline 7 & 0.83 & 0.52 & $\mathbf{1 . 0 0}$ & 0.60 & 0.56 & 0.91 & $\mathbf{1 . 0 0}$ & $\mathbf{1 . 0 0}$ & $\mathbf{1 . 0 0}$ & 0.61 & 0.53 & 0.24 & 0.73 & 0.26 \\
\hline 8 & 0.00 & 0.72 & 0.55 & 0.68 & 0.57 & 0.37 & 0.89 & 0.88 & 0.47 & 0.44 & 0.71 & $\mathbf{1 . 0 0}$ & 0.61 & 0.27 \\
\hline 9 & 0.98 & 0.63 & 0.83 & 0.41 & 0.84 & 0.80 & 0.99 & $\mathbf{1 . 0 0}$ & 0.58 & 0.88 & 0.55 & $\mathbf{1 . 0 0}$ & 0.79 & 0.20 \\
\hline
\end{tabular}

As we can observe from Table 4, various units performed differently during the study in terms of their efficiencies. Unit 2 represents the best performer since it was efficient in 11 months. Units 8 represents the worst performer since it was efficient only once during the year. The mean and the standard deviation of efficiencies for various units are presented in the last two columns of Table 4. According to the numbers, while unit 3 was efficient only once but it could manage to maintain an average of 0.82 with relatively low standard deviation, 0.15 , which is far better than the average efficiencies of units 4 and 7 despite the fact that they were efficient more than once.

We repeat the study for the units located in the rural area of the province of Zanjan. Table 5 and Table 6 show the information of the number of staff members, the number of teachers, the number of cars used and the number of applicants who registered to take the necessary exams in rural area.

Table 5

The number of input values for the first three inputs for the rural area

\begin{tabular}{lllllllllll}
\hline Unit & 1 & 2 & 3 & 4 & 5 & 6 & 7 & 8 & 9 & 10 \\
\hline Staff & 4 & 4 & 4 & 4 & 4 & 4 & 4 & 4 & 4 & 4 \\
Teacher & 8 & 13 & 10 & 14 & 13 & 14 & 11 & 15 & 8 & 6 \\
Car & 8 & 13 & 10 & 14 & 12 & 14 & 11 & 14 & 8 & 6 \\
\hline
\end{tabular}

Table 6

The summary of the number of applicants who registered for the exams in rural area

\begin{tabular}{lllllllllllllll}
\hline Unit & \multicolumn{10}{c}{ Months } \\
\cline { 2 - 15 } & 1 & 2 & 3 & 4 & 5 & 6 & 7 & 8 & 9 & 10 & 11 & 12 & Mean & Std \\
\hline 1 & 45 & 71 & 68 & 120 & 100 & 115 & 75 & 84 & 94 & 58 & 88 & 57 & 82 & 23 \\
\hline 2 & 14 & 42 & 48 & 94 & 100 & 90 & 67 & 80 & 116 & 81 & 81 & 45 & 72 & 29 \\
\hline 3 & 84 & 72 & 77 & 134 & 76 & 108 & 78 & 94 & 139 & 174 & 136 & 55 & 102 & 35 \\
\hline 4 & 95 & 76 & 60 & 122 & 102 & 90 & 86 & 74 & 88 & 100 & 90 & 66 & 87 & 17 \\
\hline 5 & 93 & 82 & 86 & 160 & 149 & 158 & 116 & 137 & 147 & 162 & 152 & 63 & 125 & 36 \\
\hline 6 & 100 & 100 & 77 & 168 & 139 & 145 & 97 & 145 & 193 & 197 & 136 & 102 & 133 & 39 \\
\hline 7 & 52 & 73 & 55 & 73 & 72 & 92 & 60 & 48 & 70 & 72 & 85 & 77 & 69 & 13 \\
\hline 8 & 73 & 69 & 64 & 86 & 93 & 79 & 76 & 80 & 53 & 95 & 83 & 64 & 76 & 12 \\
\hline 9 & 30 & 32 & 26 & 43 & 34 & 53 & 21 & 31 & 34 & 87 & 59 & 40 & 41 & 18 \\
\hline 10 & 21 & 30 & 27 & 40 & 39 & 40 & 46 & 28 & 43 & 57 & 54 & 39 & 39 & 11 \\
\hline & & & & & & & & & & & & &
\end{tabular}


The numbers of applicants who were granted the required driving certificates as the necessary output of the proposed model are given in Table 7.

Table 7

The summary of the number of applicants who registered for the exams in rural area

\begin{tabular}{|c|c|c|c|c|c|c|c|c|c|c|c|c|c|c|}
\hline \multirow{2}{*}{$\begin{array}{l}\text { Unit } \\
\text { No. }\end{array}$} & \multicolumn{12}{|c|}{ Months } & \multicolumn{2}{|c|}{ Statistics } \\
\hline & 1 & 2 & 3 & 4 & 5 & 6 & 7 & 8 & 9 & 10 & 11 & 12 & Mean & Std \\
\hline 1 & 19 & 73 & 71 & 63 & 69 & 66 & 48 & 40 & 81 & 61 & 44 & 70 & 59 & 18 \\
\hline 2 & 0 & 46 & 82 & 62 & 53 & 27 & 81 & 95 & 44 & 32 & 60 & 4 & 49 & 30 \\
\hline 3 & 73 & 139 & 123 & 61 & 72 & 138 & 88 & 87 & 75 & 114 & 56 & 96 & 94 & 29 \\
\hline 4 & 51 & 85 & 139 & 99 & 95 & 115 & 43 & 149 & 57 & 28 & 70 & 175 & 92 & 46 \\
\hline 5 & 65 & 68 & 82 & 51 & 46 & 101 & 98 & 132 & 115 & 77 & 82 & 104 & 85 & 26 \\
\hline 6 & 136 & 104 & 88 & 90 & 102 & 136 & 115 & 102 & 134 & 104 & 111 & 101 & 110 & 17 \\
\hline 7 & 0 & 53 & 72 & 156 & 75 & 86 & 52 & 74 & 78 & 61 & 44 & 82 & 69 & 36 \\
\hline 8 & 117 & 37 & 69 & 147 & 57 & 3 & 161 & 65 & 56 & 44 & 80 & 59 & 75 & 46 \\
\hline 9 & 0 & 57 & 36 & 3 & 20 & 51 & 30 & 57 & 29 & 39 & 28 & 54 & 34 & 19 \\
\hline 10 & 34 & 56 & 24 & 18 & 41 & 4 & 0 & 63 & 32 & 36 & 41 & 30 & 32 & 19 \\
\hline
\end{tabular}

The results of the implementation of the proposed DEA model of this paper for the units located in the rural areas of the city of Zanjan are summarizes in Table 8.

Table 8

The summary of measuring the relative efficiencies of the units located in rural area

\begin{tabular}{lllllllllllllllll}
\hline Unit & \multicolumn{1}{c}{ The relative efficiencies of different units for various months } & \multicolumn{3}{c}{ Statistics } \\
\cline { 2 - 17 } No. & 1 & 2 & 3 & 4 & 5 & 6 & 7 & 8 & 9 & 10 & 11 & 12 & Mean & Std \\
\hline 1 & 0.28 & 0.66 & 0.72 & 0.56 & $\mathbf{1 . 0 0}$ & 0.60 & 0.56 & 0.47 & $\mathbf{1 . 0 0}$ & $\mathbf{1 . 0 0}$ & 0.69 & 0.70 & 0.69 & 0.22 \\
\hline 2 & 0.00 & 0.56 & 0.74 & 0.40 & 0.59 & 0.23 & 0.58 & 0.69 & 0.44 & 0.45 & 0.80 & 0.04 & 0.46 & 0.26 \\
\hline 3 & 0.75 & $\mathbf{1 . 0 0}$ & $\mathbf{1 . 0 0}$ & 0.43 & $\mathbf{1 . 0 0}$ & $\mathbf{1 . 0 0}$ & 0.82 & 0.82 & 0.76 & $\mathbf{1 . 0 0}$ & 0.71 & 0.77 & 0.84 & 0.17 \\
\hline 4 & 0.39 & 0.61 & $\mathbf{1 . 0 0}$ & 0.63 & $\mathbf{1 . 0 0}$ & $\mathbf{1 . 0 0}$ & 0.28 & $\mathbf{1 . 0 0}$ & 0.66 & 0.35 & 0.84 & $\mathbf{1 . 0 0}$ & 0.73 & 0.28 \\
\hline 5 & 0.56 & 0.49 & 0.62 & 0.33 & 0.51 & 0.73 & 0.71 & $\mathbf{1 . 0 0}$ & $\mathbf{1 . 0 0}$ & 0.71 & 0.86 & 0.69 & 0.68 & 0.20 \\
\hline 6 & $\mathbf{1 . 0 0}$ & 0.75 & 0.63 & 0.58 & $\mathbf{1 . 0 0}$ & 0.99 & 0.77 & 0.68 & $\mathbf{1 . 0 0}$ & 0.91 & $\mathbf{1 . 0 0}$ & 0.58 & 0.82 & 0.18 \\
\hline 7 & 0.00 & 0.38 & 0.63 & $\mathbf{1 . 0 0}$ & $\mathbf{1 . 0 0}$ & 0.73 & 0.44 & 0.73 & $\mathbf{1 . 0 0}$ & 0.90 & 0.60 & 0.60 & 0.67 & 0.30 \\
\hline 8 & $\mathbf{1 . 0 0}$ & 0.28 & 0.50 & 0.94 & 0.64 & 0.03 & $\mathbf{1 . 0 0}$ & 0.44 & 0.95 & 0.56 & $\mathbf{1 . 0 0}$ & 0.35 & 0.64 & 0.33 \\
\hline 9 & 0.00 & 0.92 & 0.60 & 0.03 & 0.56 & 0.75 & 0.67 & 0.83 & 0.77 & 0.54 & 0.54 & 0.54 & 0.56 & 0.28 \\
\hline 10 & $\mathbf{1 . 0 0}$ & 0.97 & 0.40 & 0.21 & $\mathbf{1 . 0 0}$ & 0.78 & 0.00 & $\mathbf{1 . 0 0}$ & 0.71 & 0.71 & 0.91 & 0.53 & 0.69 & 0.34 \\
\hline
\end{tabular}

As we can see from Table 2, unit 3 represents the best performer among all other units. It was efficient five times with the mean and standard deviation of 0.84 and 0.17 , respectively. Unit 6 is the second best performer with an average efficiency of 0.82 and standard deviation of 0.18 , respectively. Unit 2 was the worst performer since it was not considered to be efficient and maintained a low average efficiency of 0.46 . Unit 4 was efficient five times but it represented a low performance in other periods and consequently ended up having low average on efficiency. The other units provided an average of above 50 percent, which means that they could possibly increase their efficiencies by reducing their inputs and increasing their output.

One important observation from comparing the results of Table 4 and Table 8 is that the average efficiencies of nine units located inside the city is 80 percent while the average efficiencies of ten units located outside the city is about 68 percent. A brief study on the customer backgrounds reveals that the units located inside the cities serve more people who higher level of educations. The other observation is that the units located inside the city always have some registered people who wish to take part in exams but the units located in rural area could not give examination occasionally because no applicant registered. 


\section{Conclusion}

In this paper, we have presented an empirical study on the implementation of DEA method for private organizations responsible for training and giving the necessary written and driving tests. The proposed DEA model of this paper considered four inputs including the numbers of staff members, teachers, cars and participants. We have considered only the number of people who passed the examinations successfully as the main output criteria. The proposed model was tested on two groups of private organizations located in the city and the rural area and the results have been compared and analyzed.

The research can be extended in different ways. One of the necessary open questions is to detremine the main reasons for failure on test drive. The present study did not have any access to such data and gethering the necessary data needed a comprehensive survey with questionnare which was beyound the scope of this research. A good work could normally focus to detremine the common reasons for failure on test drive exams and provide necessary steps to prevent them. We leave this as future research for interested researchers.

\section{Acknowledgment}

The authors would like to thank the anonymous referees for their constructive comments on earlier version of this work.

\section{References}

Bessent, A., \& Bessent. E. W. (1980). Determining the comparative efficiency of schools through data envelopment analysis. Educational Administration Quarterly, 16, 57-75.

Bessent, A., Bessent, E. W., Kennington, L. J., \& Reagan, B. (1982). An application of mathematical programming to assess productivity in the Houston independent school district. Management Science, 28, 1355-1367.

Borge, L.-E., \& Naper, L. R. (2006). Efficiency potential and efficiency variation in Norwegian Lower Secondary Schools. FinanzArchiv, 62(2), 221-249.

Charnes A, Cooper, W. W., \& Rhodes, E. (1978). Measuring the efficiency of decision making units. European Journal of the Operational Research, 2, 429-44.

Charnes A, Cooper W. W., Lewin, A., \& Seiford, L. M. (1994). Data envelopment analysis: theory, methodology and applications. Massachusetts: Kluwer Academic Publishers.

Chakraborty, K., Biswas, B., \& Lewis, W. C. (2001). Measurement of Technical Efficiency in Public Education: A Stochastic and Nonstochastic Production Function Approach. Southern Economic Journal, 67, 889-905.

Deller, S. C., \& Rudnicki, E. (1993). Production efficiency in elementary education: The case for Maine public schools. Economics of Education Review, 12(1), 45-57.

Hanushek, Eric A. (1986). The economics of schooling: Production and efficiency in public schools. Journal of Economic Literature, 24, 1141-77.

Kaplan, R.S. \& Norton, D.P. (1992). The balanced scorecard - measures that drive performance. Harvard Business Review, 70(1), 71-79.

Kaplan, R.S. \& Norton, D.P. (2004), Strategy maps: converting intangible assets into tangible outcomes, Harvard Business School Press, Boston, MA.

Najafi, S. E., Ahmadi, S. A., Fallah, M. \& Shahsavaripour, N. (2011). A cause and effect two-stage BSC-DEA method for measuring the relative efficiency of organizations. Management Science Letters, 1(1), 2011. 
Naper, L. R. (2010). Teacher hiring practices and educational efficiency. Economics of Education Review, 29, 658-668.

Ray, S. C. (1991). Resource-use efficiency in public schools: A study of Connecticut data. Management Science 37:1621-8.

Walberg, H., \& Fowler, W. (1987). Expenditure and size efficiencies of public school districts. Educational Researcher, 16, 5-13.

Roghanian, E. \& Foroughi, A. (2010). An empirical study of Iranian regional airports using robust data envelopment analysis. International Journal of Industrial Engineering Computations, 1(1), 65-72. 